\title{
La tribu de los HOYGAN
}

\author{
José Roberto Saravia Vargas
}

\section{6 lgunos piensan que 4 es un mito; creen que Lno se trata sino de un} ardid de los Puristas para mantener su hegemonía. No existe nada más alejado de la verdad. Empezaremos nuestra exploración por este preciso cuadrante de este mundo y sin duda alguna divisaremos unos cuantos miembros de la tribu de los HOYGAN. Quienes nunca hayan explorado antes y carezcan de experiencia, hagan pareja con exploradores más experimentados. En cuanto divisen algún HOYGAN, sean cautelosos. Bajo ninguna circunstancia los provoquen, ya que poseen una naturaleza extremadamente violenta. Si un grupo de ellos los hostiga, retrocedan inmediatamente EN ABSOLUTO SILENCIO Y SIN PROVOCARLOS. ¿Está claro?"

El grupo de exploradores respondió “Señor, sí, señor!” a su comandante, al unísono. "Por fortuna", pensó ste, "hoy son pocas las parejas. Es mucho más complicado cuando los novatos abundan".

"AActiven sus dispositivos miméticos y andando!", ordenó después de un minuto.

Anduvieron por ese sector con cautela. El entorno era una selva donde sin duda alguna Pinto, Rojas, Chacón y Pineda (los novatos) se habrían perdido. Afortunadamente Alcázar, Darío, Martí y Lyra los acompañaban.

"¿Y por qué los llaman HOYGAN?", preguntó Rojas a Lyra lleno de curiosidad.

"Espera y lo sabrás", respondió ella ocultando una sonrisa.

Rojas era un novato que se creía muy experimentado. Insistía en alejarse de Lyra y explorar por su cuenta. Aprovechó un momento en que la exploradora aseguraba el perímetro para escapar de su supervisión. Lyra lo divisó mientras se dirigía solo y descuidadamente hacia uno de los lugares más peligrosos, un Sitio de Torrentes.

Desgraciadamente, el testarudo joven hizo caso omiso de las llamadas de su pareja, a quien no le quedó más remedio que perseguirlo hasta el corazón mismo del Sitio de los Torrentes. Torrentes de todos tipos y tamaños se observaban por doquier. Constituían sin duda un tentador atractivo para los HOYGAN.

Súbitamente fueron abordados por uno de los HOYGAN, quien saltó sobre ellos de entre unos arbustos y les gritó con una voz tan fuerte como se la permitieron sus cuerdas vocales:

"HOYGAN!!! NESECITO SAVER ONDE VAJAR LA PELIQLA DE HESTAR WARS GRATIX. KOMO Y ONDE LOAGO????". 
Rojas entró en pánico por la sorpresa y gritó. El HOYGAN interpretó dicha reacción como una señal de escucha y atención, por lo que se arrojó directamente sobre el explorador novato. Gritaba a todo pulmón mientras lo zarandeaba con violencia:

"PORFABORPORFABORPORFABOR... GRAX D HANTEBRASO!!!”.

Lyra trató de hacerse cargo de la situación, pero se había generado un barullo tal que atrajo a otros HOYGAN, quienes los rodearon al instante mientras vociferaban en una sinfonía del desorden:

"HOYGAN KOMOSE JAKEA GUINDOSBISTA? ME PID LA KLAB I NO LA C!".

"HOYGAN KIEN TI N ANIME VUENO KE MEMA ND CRIES KONPLETAS AL KORREO EN ESPESIAL EBANJELION I LSO KBAYEROS D SODHIAKO, O SAN SEILLA GRAX Y PERDON SI PIDO MUX”.

"HOYGAN ALLUDEN MEN HA JAKIAR LA KOMPU DE MI NOBIA LLO NO C MUCHO”.

Lyra envió una señal de ayuda y rápidamente acudieron los equipos de Darío y Martí, quienes crearon distracciones para poner a salvo a Rojas. Por indicación del comandante, mediante los comunicadores, tuvieron que sedarlo para que dejara de gritar. Minutos después se unieron a ellos Alcázar y el comandante. Hordas de HOYGAN los habían descubierto y se acercaban hacia ellos ruidosamente.

“Señor, ¿cómo procedemos?”, interrogó Martí mientras una gota de sudor se deslizaba silenciosamente desde su sien izquierda a su oreja.

"¡Abortamos la misión. Código Ctrl+Alt+Esc!", ordenó el comandante.

$* * * * * * * * * * * * * * * * * * * * * * * * * * * * *$

"Rubén, el juego de hoy estuvo intenso. ¿No te parece?", inquirió Martí a Darío.

“EEstuvo terrible, José! ¡De no haber sido por Carmen, ese novato de Rojas hubiera perdido!", respondió este mientras se quitaba los guantes para luego remover su casco de Realidad Virtual.

"Sí; esa Lyra va a llegar a comandante algún día; estoy seguro", agregó Martí.

Cuando salían de la cámara, encontraron a Huidobro, quien había jugado ese día como su comandante.

"Estuvimos cerca en el juego de hoy, ¿verdad, Vicente?”. le dijo Darío.

"Demasiado cerca. Si Rojas hubiese perdido, los equipos de James y de Miguel tomarían mucha más ventaja y sería prácticamente imposible para nosotros alcanzarlos la próxima vez que entráramos al ciberespacio a jugar", respondió este.

"Sí. ¡Cervantes y Joyce son todos unos veteranos!", asintieron los otros dos mientras se alejaban por el pasillo. 